\title{
Simulation of Mosul Dam Break Using Finite Volume Method
}

\author{
Ayhan H. Saleem*, Jowhar R. Mohammad \\ Department of Water Resources Engineering, University of Duhok, Duhok, Kurdistan Region, Iraq
}

\author{
*Corresponding author: \\ Ayhan H. Saleem, \\ Department of Water \\ Resources Engineering, \\ University of Duhok, Duhok, \\ Kurdistan Region, Iraq. \\ E-mail: ayhan.saleem@ \\ uod.ac \\ Received: 02 February 2020 \\ Accepted: 04 March 2020 \\ Published: 30 December 2020 \\ DOI \\ 10.25156/pti.v10n2y2020.pp10-20
}

\section{A B S TR A C T}

Mosul dam is an earth-fill embankment located north of Iraq on the Tigris River forming a reservoir with $11.11 \mathrm{~km}^{3}$ water storage capacity which is the largest dam in the country. The dam is built on a rock bed foundation, in which the dissolution process is dynamic in the zone where gypsum and anhydrite layers present. During the construction development seepage locations were found in the dam foundation and the grouting process is in progress until now to control this problem. Therefore, the possibility of the Mosul dam break is highlighted by previous studies. In this research, a FORTRAN code based on the finite volume method is modified to solve the two-dimensional shallow water equations and simulating the Mosul dam break. The computational domain discretized using unstructured triangular mesh. The solver applied Harten lax van leer with contact (HLLC) wave approximate Riemann solver to calculate the cell interface fluxes, and the semi-implicit scheme employed to solve the friction source term. The numerical scheme applied to two benchmark test cases, and the results showed that the presented model was robust and accurate especially in handling wet/dry beds, mixed flow regimes, discontinuities, negative water depths, and complex topography. The results of this study demonstrate that flood waves may reach the center of Mosul city in $<6 \mathrm{~h}$ and water depth may rise to $34 \mathrm{~m}$ after $7 \mathrm{~h}$ of Mosul dam breaking. Finally, the simulation results of the Mosul dam break were used to prepare an emergency action plan.

Keywords: Dam break; Emergency action plan; Finite volume method; Harten lax van leer with contact scheme; Unstructured grid

\section{INTRODUCTION}

Mosul dam, which is considered as the largest hydraulic structure in Iraq, constructed in the 1980s, located in Mosul city about $50 \mathrm{~km}$ from the northwest. The dam is a multifunction project for flood control, irrigation, and hydropower generation which produces electricity for the majority of Mosul city. It impounds water from the Tigris River forming a reservoir with $11.11 \mathrm{~km}^{3}$ of the water storage capacity of $8.16 \mathrm{~km}^{3}$ live and $2.95 \mathrm{~km}^{3}$ dead storage. It is an earth-fill embankment with clay core covered by graded filters on the upstream and downstream sides, a powerhouse, bottom outlet, concrete-lined gated spillway, and a fuse plug secondary spillway. The slope of the upstream and downstream embankment below $330 \mathrm{~m}$ a.s.l. is 2.5:1 (horizontal: vertical) which is the normal operation level, above $330 \mathrm{~m}$ a.s.l. both slopes are 1.73:1. The dam is $2100 \mathrm{~m}$ long, $100 \mathrm{~m}$ high, and $10 \mathrm{~m}$ top width, as shown in Figure 1. The total dam construction cost was evaluated by 2.6 billion USD at the cost level of the 1980 s.

The Mosul dam is built on a rock bed foundation consists of marls, chalky limestone, gypsum, anhydrite, and limestone.
During the construction of the dam sinkholes, voids and cracks were discovered in the foundation which refers that dissolution development is dynamic in the zone where gypsum and anhydrite layers present (Wakeley et al., 2007). Due to the previous studies, seepage in the foundation is the main reason for dissolution in the gypsum layer produce cavities that demand the grouting treatment process and its rates related to seepage velocity and hydraulic gradient. The dissolution amount at Mosul dam per day is fluctuated between 42 and 80 tons and extends $100 \mathrm{~m}$ below the dam bed (Guzina et al., 1991). This development with the evaporitic rocks, dolomite, karstic limestone, and calcareous marls provides critical foundation situations underneath the Mosul dam. Therefore, through the construction development grouting processes performed to stop seepage under the foundation. Unfortunately, no operation has yet been undertaken successfully because in 1986 other seepage locations were documented. Until now, the grouting process is in progress and many studies have been conducted to conquer this issue. According to a study by the US Army Corps of Engineers, the possibility of the Mosul Dam failure is highlighted (Wakeley et al., 2007). The most detailed studies on Mosul dam failure are (Swiss- 


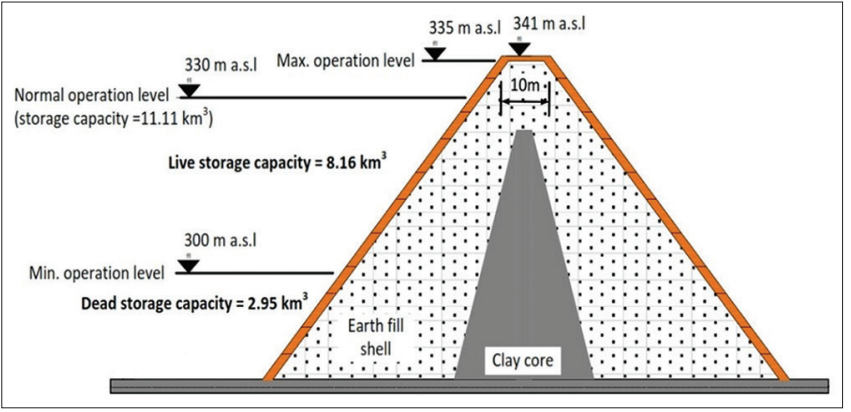

Figure 1: Sketch of Mosul dam body cross-section (Adamo et al., 2017)

Consultants, 1984) applied flow in river system which is a one-dimensional mathematical model and different dam failure scenarios were investigated, Annunziato et al., 2016, provided a report from joint research center European Commission implemented a two-dimensional computer code (HyFlux2) and various water level in the dam has been studied assuming breach area is about $26 \%$.

In this study, a finite volume method (FVM) will be used to solve a two-dimensional shallow water equations (SWE) for simulating the Mosul dam break to examine the flood damage of this event through preparing emergency action plan (EAP). The two-dimensional simulation of the Mosul dam-break flow can present sufficient information about a potential flood at the downstream of the dam such as water depth time series on the area, the velocity of the flow, and time arrival of the front wave. The FVM is based on the integral form of the equation and the fundamental factors; mass and momentum remain conserved through the discretization (Hirsch, 2007). Therefore, it is more straightforward to construct a conservation scheme form to capture a shock wave (Valiani et al., 2002). The FVM applied in this research is a modification of developed FORTRAN code in which Roe approximate Riemann solver is employed to evaluate the cell interface fluxes, which is based on a linearization involving of eigenvectors and eigenvalues of the approximate Jacobean matrix. The present work applied The Harten lax van leer with contact (HLLC) wave approximate Riemann solver developed by (Toro, 2001) to compute fluxes which are based on a calculation of the right, middle (contact), and left wave speed. In the last decade, the HLLC scheme has been implemented by many researchers such as Liang and Borthwick, 2009, Song et al., 2011, Hou et al., 2013, and Bi et al., 2015 and it is revealed that the scheme is robust, able to manage wet/dry interfaces, deal with mixed flow regimes, and accurate on irregular topography in flow problem modeling. The friction source terms have been treated by a semi-implicit method to control the numerical oscillation problem due to small water depth near the wet/dry region and a novel Courant Friedrichs Lewy (CFL) specification has been applied to compute the appropriate time stepping.
As a pre-processing step, the considered area is divided into unstructured triangular grid mesh.

\section{GOVERNING EQUATIONS}

The time-dependent 2D SWEs in conservative matrix form through source terms such (Song et al., 2011) used as follows:

$$
\frac{\partial U}{\partial t}+\frac{\partial E}{\partial x}+\frac{\partial G}{\partial y}=S
$$

The variables $U, t, E, G$ and $S$ respectively, represent, the flow variables vector, time, fluxes component along with $x$ and $y$ directions and source terms; in which

$$
\begin{gathered}
U=\left[\begin{array}{c}
b \\
b u \\
h v
\end{array}\right], E=\left[\begin{array}{c}
b u \\
b u^{2}+\frac{1}{2} g b^{2} \\
b u v
\end{array}\right], G=\left[\begin{array}{c}
b v \\
b w v \\
b v^{2}+\frac{1}{2} g b^{2}
\end{array}\right] \\
S=S_{0}+S_{f}=\left[\begin{array}{c}
0 \\
g h S_{0 x} \\
g h S_{0 y}
\end{array}\right]-\left[\begin{array}{c}
0 \\
g h S_{f x} \\
g h S_{b y}
\end{array}\right]
\end{gathered}
$$

Where $h, u, v$ and $g$ are, respectively, the water height, averaged flow velocity in $x$ and $y$ directions, and gravity acceleration; $\left(S_{0} x=-\partial z \partial \partial x, S_{0 y}=-\partial \not \partial \partial y\right)$ and $\left(S_{f,}, S_{f j}\right)$ denotes the bed and friction slopes in the $x$ and $y$ directions, herein $z$. is a bed elevation. The bottom friction slopes are evaluated by employing the Manning equation

$$
S_{f x}=\frac{n^{2} u \sqrt{u^{2}+v^{2}}}{b^{4 / 3}}, S_{f y}=\frac{n^{2} v \sqrt{u^{2}+v^{2}}}{b^{4 / 3}}
$$

where $n$ is the Manning coefficient.

\section{THE NUMERICAL SCHEME}

\section{Finite Volume Discretization over Unstructured Triangular Grid for Two-dimensional SWE}

The computational domain is divided into a subdomain with arbitrary triangular cells called control volumes. The average fluid variables are saved at each cell center. The integral form of equation (1) is:

$$
\frac{\partial}{\partial t} \int_{\Omega} U d \Omega \int_{\Omega}\left(\frac{\partial E}{\partial x}+\frac{\partial G}{\partial y}\right) d \Omega \int_{\Omega} S d \Omega
$$

writing equation (5) in another form as 


$$
\frac{\partial}{\partial t} \int_{\Omega} U d \Omega+\int_{\Omega} \operatorname{div} F d \Omega=\int_{\Omega} S d \Omega
$$

where

$$
\operatorname{div}=\frac{\partial}{\partial x} \overrightarrow{\mathrm{i}}+\frac{\partial}{\partial y} \overrightarrow{\mathrm{j}}, \quad F=E \overrightarrow{\mathrm{i}}+G \overrightarrow{\mathrm{j}}
$$

The divergence theorem is definite as

$$
\int_{\Omega} \operatorname{div} F d \Omega=\int_{\Gamma} F \cdot n d \Gamma
$$

The integral of the divergence of $F$ vector on a domain $\Omega$ is equivalent to $F$ in the direction of $n$ outward vector normal to the surface element $d \Gamma$ which bounds the domain summed over the whole bounding surface. Substituting equation (8) in equation (6) gives the following equation

$$
\frac{\partial}{\partial t} \int_{\Omega} U d \Omega \int_{\Gamma} F \cdot n d \Gamma=\int_{\Omega} S d \Omega
$$

Where $\Omega$ represent the domain, $\Gamma$ is the perimeter of the $\Omega, n$ is the normal vector external of the $\Gamma$ specified by $\left(n_{x}, n_{y}\right)^{T}$ and $F \cdot n$ is the flux vector normal to the $\Gamma$ in which stated as

$$
F(U) \cdot n=\left[\begin{array}{c}
b u_{\perp} \\
b u u_{\perp}+\frac{1}{2} g b^{2} n_{x} \\
b v u_{\perp}+\frac{1}{2} g b^{2} n_{y}
\end{array}\right]
$$

Where $u_{\perp}=u n_{x}+v n_{y}$ is the perpendicular velocity to the cell edge. The line integral of the $F(U) \cdot n$ overall triangular cell faces can be expressed in algebraic form as

$$
\int_{\Gamma} F(U) \cdot n d \Gamma=\sum_{k=1}^{3} F_{k}\left(U_{L}, U_{R}\right) \cdot n_{k} L_{k}
$$

Where $k$ denotes the face index, $L$ represents the face length and $U_{L}, U_{R}$ are the Riemann left and right conditions. The discretization of equation (9) over complex triangular cell $C_{i}$ yields

$$
\Omega_{i} \frac{d U_{i}}{d t}=-\sum_{k=1}^{3} F_{i, k}\left(U_{L}, U_{R}\right) \cdot n_{i, k} L_{i, k}+S_{i}
$$

Where $\Omega_{i}$ is the area of the cell $C_{i} U_{i}$ represents the cell average variables and $i, k$ are the index of cell and face.

\section{The Finite Volume Code and Modifications}

The unstructured finite volume code modified in this study was first developed and applied by Mohammad, 2007. The code is written in Fortran language to solve the twodimensional SWE. In this model, the Roe's approximate Riemann solver was implemented to evaluate the fluxes. The solver used the nonlinear limiter and predictorcorrector time stepping to present second-order precision in spatial and temporal discretization, respectively. The developed scheme is able to deal with wet/dry front, dam-break flood wave, subcritical and supercritical flows, and other practical cases. The comprehensive steps of the algorithm are shown in Figure 2. The Fortran code has been read and understand at each step then modified. In this research, the code improved with an option by adding two more subroutines to the algorithm structure. The main changes made are; as a pre-processing step the computation domain is discretized to an unstructured triangular grid, the HLLC approximate Riemann solver is implemented to compute the fluxes, the friction source term is solved by the semi-implicit scheme and for time-stepping, a novel

\section{Main program}

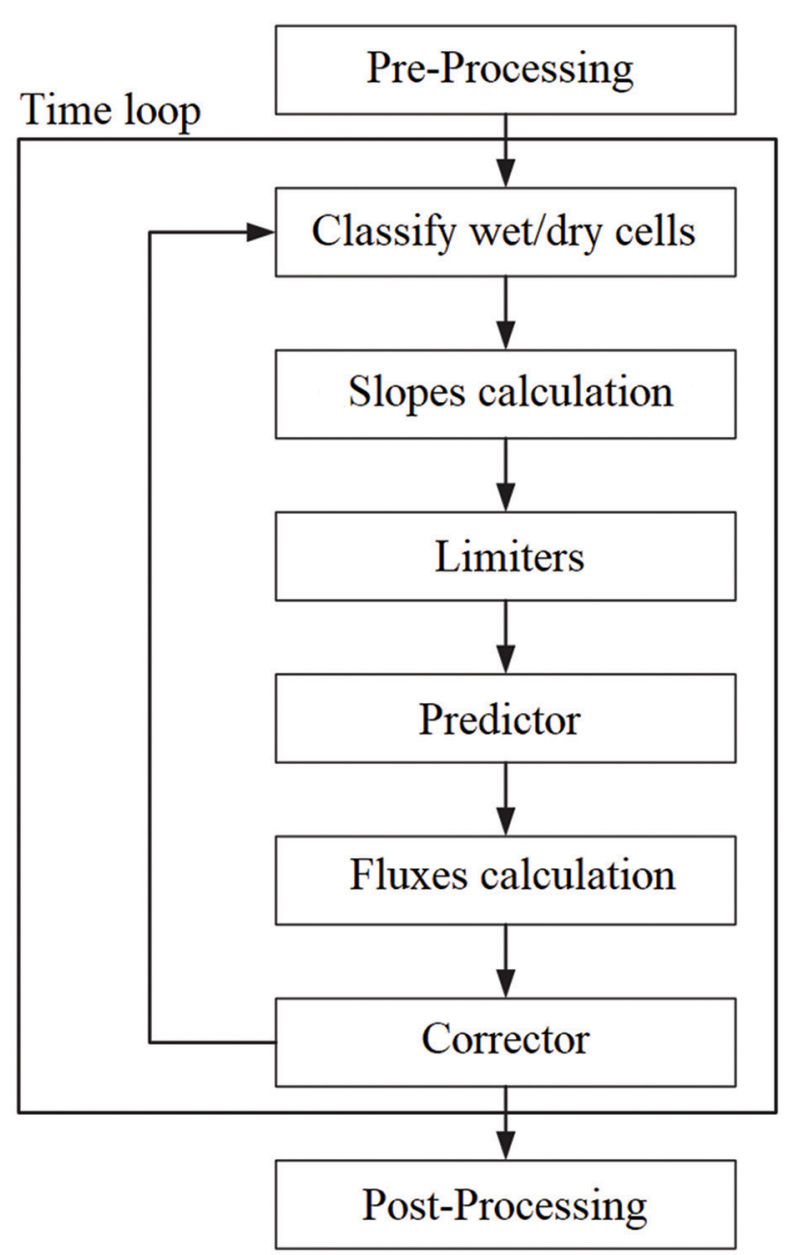

Figure 2: Algorithm flowchart 
CFL is applied. The major modified parts of the algorithm model are described as follows:

\section{Grid Generation and Data Structure}

The computational domain is divided into non-overlapping unstructured triangular cells using Point wise v18.1 R2 mesh generation software. The grid exported from the program by a special Plugin SDK solver which contains two fundamental elements cell and node. The output data are used in a developed MATLAB code to produce the edge and neighbor cells. Further, the grid topography is categorized by three nodes (vertices), three edges, and three or less neighbors. The node has $x, y$, and $z$ coordinates and numbered in a counterclockwise direction as demonstrated in Figure 3. The edge has a start and end nodes, if the edge is joint with another cell and then the edge is identified as an interior edge. However, if it is not shared then the edge is labeled as boundary edge and the cell has three or less neighbors are numbered in the same manner as the nodes, as shown in Figure 4. In addition, the area of the triangular cell $C_{i}$ and the unit outward normal vector $n$ are evaluated by equations (13) and (14).

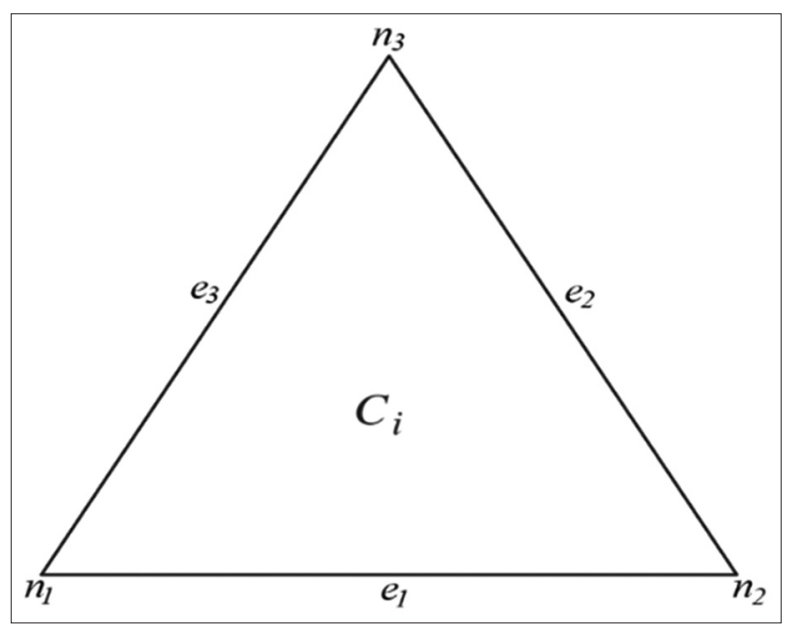

Figure 3: Triangular cell diagram with three noes and edges

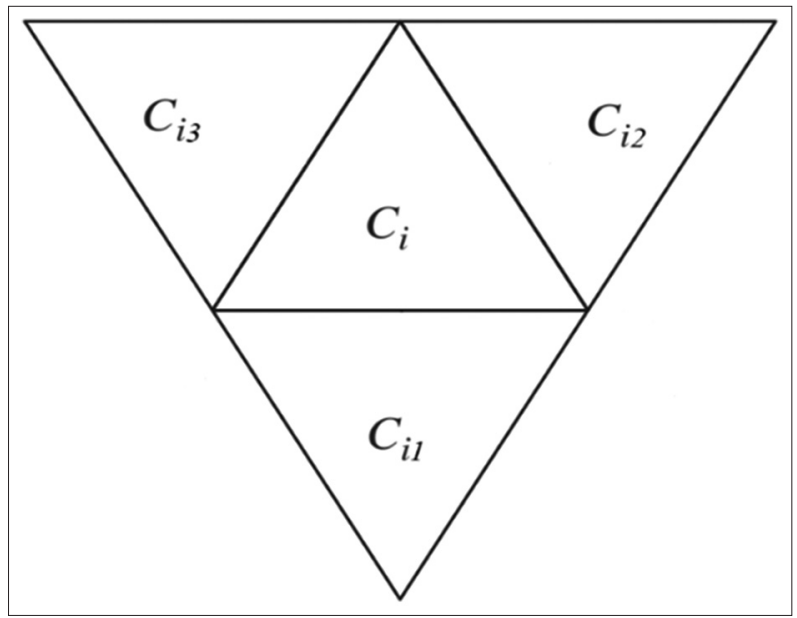

Figure 4: Triangular cell diagram with three neighbors

$$
\begin{aligned}
& \Omega_{i}=\frac{1}{2}\left[\begin{array}{l}
\left(x_{1}-x_{2}\right)\left(y_{1}+y_{2}\right)+\left(x_{2}-x_{3}\right)\left(y_{2}+y_{3}\right) \\
+\left(x_{3}-x_{1}\right)\left(y_{3}+y_{1}\right)
\end{array}\right] \\
& n=\left[\begin{array}{l}
n_{x} \\
n_{y}
\end{array}\right]=\frac{1}{\sqrt{\left(x_{e}-x_{s}\right)^{2}+\left(y_{e}-y_{s}\right)^{2}}}\left[\begin{array}{l}
y_{e}-y_{s} \\
x_{e}-x_{s}
\end{array}\right]
\end{aligned}
$$

Where, $\Omega_{i}$ represents the calculated area. If $\Omega>0$ it means that nodes are in counter-clockwise direction, otherwise the index of $n_{2}$ and $n_{3}$ should be replaced with the minus sign of area $-\Omega_{i}$. The coordinates $\left(x_{e}-x\right)$ and $(y-y)$ are of start and endpoint of the face.

\section{Interface Flux Computation}

The HLLC wave approximate Riemann solver developed by Toro, 2001, has been applied in this research since it is an appropriate model to wet/dry interface cases and entropy satisfaction. The HLLC interface flux is calculated as follows:

$$
F\left(U_{L}, U_{R}\right) \cdot n= \begin{cases}F_{L} & \text { if } S_{L} \geq 0 \\ F_{*_{L}} & \text { if } S_{L}<0 \leq S_{M} \\ F_{*_{R}} & \text { if } S_{M}<0 \leq S_{R} \\ F_{R} & \text { if } S_{R} \leq 0\end{cases}
$$

Where $F_{L}=F\left(U_{L}\right) \cdot n$, and $F_{R}=F\left(U_{R}\right) \cdot n$ are calculated by equation (10) and $F_{* \mathrm{~L}}, F_{* \mathrm{R}}$ represent the left and right fluxes at the middle region of the Riemann solution beside the contact wave and computed as Hou et al., 2013, which are defined as:

$$
\begin{gathered}
F_{* L}=\left[\begin{array}{c}
\left(E_{H L L}\right)^{1} \\
\left(E_{H L L}\right)^{2} n_{x}-u_{/ /, L}\left(E_{H L L}\right)^{1} n_{y} \\
\left(E_{H L L}\right)^{2} n_{y}+u_{/ /, L}\left(E_{H L L}\right)^{1} n_{x}
\end{array}\right] \\
F_{* R}=\left[\begin{array}{c}
\left(E_{H L L}\right)^{1} \\
\left(E_{H L L}\right)^{2} n_{x}-u_{/ /, R}\left(E_{H L L}\right)^{1} n_{y} \\
\left(E_{H L L}\right)^{2} n_{x}-u_{/ /, R}\left(E_{H L L}\right)^{1} n_{y}
\end{array}\right]
\end{gathered}
$$

Where $u / /=-u n+v n_{x}$ is the tangential velocity to the cell edge and $\left(E_{H L L}\right)^{1}$ and $\left(E_{H L L}\right)^{2}$ are the first and second components of Harten normal flux $E_{H L L}$ and given by

$E_{H L L}=\frac{S_{R} F\left(U_{L}\right)-S_{L} F\left(U_{R}\right)+S_{L} S_{R}\left(U_{R}-U_{L}\right)}{S_{R}-S_{L}}$

in which $\left(U_{L}, U_{R}\right)$, is calculated by 


$$
U=\left[\begin{array}{c}
b \\
b u_{\perp} \\
b u_{/ /}
\end{array}\right]
$$

The terms $S_{L}, S_{M}$ and $S_{R}$ represent the left, middle (contact), and right wave speeds as presented in Figure 5 and given by:

$$
S_{L}=\left\{\begin{array}{cc}
\min \left(u_{\perp, L}-\sqrt{g h_{L}}, u_{\perp, *}-\sqrt{g h_{*}}\right) & \text { if } h_{L}>0 \\
u_{\perp, R}-2 \sqrt{g h_{R}} & \text { if } h_{L} \mid=0
\end{array}\right.
$$

$S_{R}=\left\{\begin{array}{lr}\max \left(u_{\perp, R}+\sqrt{g h_{R}}, u_{\perp, *}+\sqrt{g h_{*}}\right) & \text { if } h_{R}>0 \\ u_{\perp, L}-2 \sqrt{g h_{L}} & \text { if } h_{R} \mid=0\end{array}\right.$

Where $u_{\perp, \mathrm{L}}, u_{\perp, R}, h_{L}$ and $h_{R}$, respectively, denote the Riemann left and right initials and the middle components. $u_{\perp, *}$ and $h_{*}$ are calculated by:

$$
\begin{gathered}
u_{\perp, *}=\frac{1}{2}\left(u_{\perp, L}+u_{\perp, R}\right)+\sqrt{g h_{L}}-\sqrt{g h_{R}} \\
h_{*}=\frac{1}{g}\left[\frac{1}{2}\left(\sqrt{g h_{L}}+\sqrt{g h_{R}}\right)+\frac{1}{4}\left(u_{\perp, L}-u_{\perp, R}\right)\right]^{2}
\end{gathered}
$$

And $S_{M}$ is expressed as:

$$
S_{M}=\frac{S_{L} h_{R}\left(u_{\perp, R}-S_{R}\right)-S_{R} h_{L}\left(u_{\perp, L}-S_{L}\right)}{h_{R}\left(u_{\perp, R}-S_{R}\right)-h_{L}\left(u_{\perp, L}-S_{L}\right)}
$$

\section{Source Term Treatment}

As shown in equation (3), the source terms are divided into slope and friction terms. In this research, following (Song et al., 2010) the bed slope source terms which have the form $S_{i, 0 x}=\left(0, S_{i, 0 x x}, S_{i, 9} y\right)^{T}$ are calculated by:

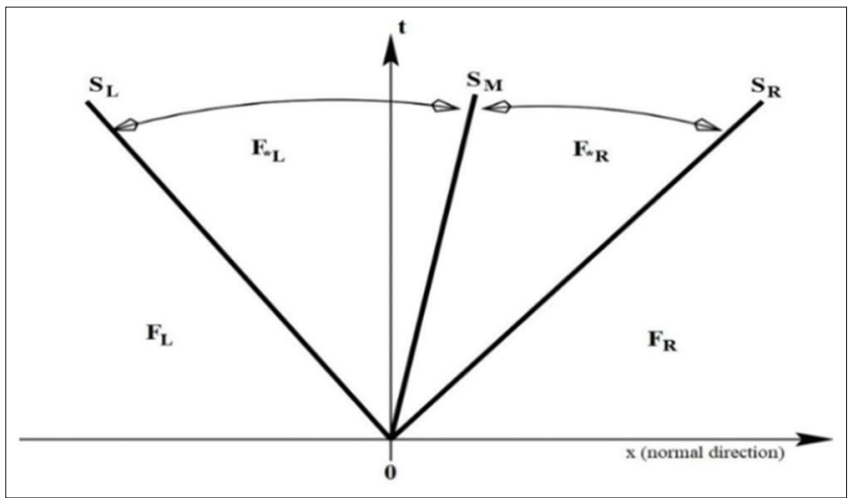

Figure 5: HLLC solution of approximate Riemann solver

$$
\begin{gathered}
S_{i, 0 x}=-\int_{C_{i}} g h \alpha_{i} d \Omega=-g \alpha_{i} \int_{C_{i}} h d \Omega=-g \alpha_{i} h_{i} \Omega_{i} \\
S_{i, 0 y}=-\int_{C_{i}} g h \beta_{i} d \Omega=-g \beta_{i} \int_{C_{i}} h d \Omega=-g \beta_{i} h_{i} \Omega_{i}
\end{gathered}
$$

The water depth is horizontal when the velocity becomes zero and where $h>0, \partial z \partial x=-\partial h \partial x$ and $\partial z / \partial y=(-\partial \mathrm{h}) /(\partial \mathrm{y}$, and become:

$$
\begin{aligned}
S_{i, 0 x}= & -\int_{C_{i}} g h \frac{\partial z}{\partial x} d \Omega=\int_{C_{i}} \frac{\partial}{\partial x}\left(\frac{1}{2} g h^{2}\right) d \Omega=\int_{\partial C_{i}} \frac{1}{2} g h^{2} n_{x} d l \\
& =\sum_{k=1}^{3} \frac{1}{2} g\left(h_{i, k}^{\mathrm{Rec}}\right)^{2} l_{i, k} n_{x, k} \\
S_{i, 0 y}= & -\int_{C_{i}} g h \frac{\partial z}{\partial y} d \Omega=\int_{C_{i}} \frac{\partial}{\partial y}\left(\frac{1}{2} g h^{2}\right) d \Omega=\int_{\partial C_{i}} \frac{1}{2} g b^{2} n_{y} d l \\
& \sum_{k=1}^{3} \frac{1}{2} g\left(h_{i, k}^{\mathrm{Rec}}\right)^{2} l_{i, k} n_{y, k}
\end{aligned}
$$

Where $z$ is the center bed elevation of the $k_{t b}$ face and $i_{t b}$ cell, $n_{x}, n_{y}$ are the normal unit outward vector components and $b^{\text {Rec }}$ represents the reconstructed water depth. The friction source term has been treated by the semi-implicit method as Bi et al., 2015, which can be expressed as:

$$
\begin{aligned}
u^{n+1} & =\frac{1}{1+\Delta t \hat{\tau}^{n}} \hat{u}^{n} \\
v^{n+1} & =\frac{1}{1+\Delta t \hat{\tau}^{n}} \hat{v}^{n}
\end{aligned}
$$

where $\hat{\tau}^{n}=g n^{2} \sqrt{\left(\hat{u}^{n}\right)^{2}+\left(\hat{v}^{n}\right)^{2}}\left(\hat{b}^{n}\right)^{-4 / 3} ; \hat{u}^{n}, \hat{v}^{n}$ and $\hat{b}^{n}$, are the primary values in friction source term solving.

\section{Boundary Conditions}

The ghost cells are implemented for calculating fluxes at boundary cells as Anastasiou and Chan, 1997. The boundary conditions are divided into three types; wall, inflow and open boundary, and water depth at ghost cells for all types of boundary conditions are equal to boundary cells. The velocity components at the ghost cell for wall and inflow boundaries are assigned a negative value of boundary cells while for open boundary the ghost cell velocities are the same as boundary cells.

\section{Stability Conditions}

The CFL is utilized to manage the stability of an explicit numerical scheme. The CFL specification is applied to calculate a suitable time stepping (Song et al., 2011) which given by 


$$
\Delta t=C F L \cdot \min _{i, k}\left(\frac{\Omega}{\left(\left|u_{\perp}\right|+\sqrt{g h}\right)_{k} L_{k}}\right)_{i}
$$

where $\Delta t$ represents the time step, and $i, k$ are cell and face index, respectively. In this research, the CFL value ranging between 0.7 and 0.8 is implemented.

\section{RESULTS AND DISCUSSION}

\section{Model Verification}

The roe and HLLC model are validated by applying three benchmark tests with wet/dry front using unstructured triangular mesh.

\section{Two-dimensional partial dam break with wet/dry bed test cases}

In this test, the horizontal two-dimensional frictionless dam break with $200 \times 200 \mathrm{~m}^{2}$ domain has been considered to validate the presented models. The initial water depth is $10 \mathrm{~m}$ at the upstream and the downstream is studied for two cases $5 \mathrm{~m}$ and dry bed. The breach is $75 \mathrm{~m}$ wide, $95 \mathrm{~m}$ from the bottom and $30 \mathrm{~m}$ from the top, as shown in Figure 6. The computational domain is divided into 5630 triangular cells and 2955 points, as presented in Figure 6. The Roe and HLLC code were run up to $7.2 \mathrm{~s}$ with $0.1 \mathrm{~s}$ time step Figure 7 for wet bed and Figure 8 for a dry bed. These figures show the contour line of the water depth in the computational domain considered in this study. As it can be observed almost all the results produced from both schemes are qualitatively and quantitatively similar. This reveals that both schemes perform the same in simulating dam beak problems. Further, the 3D view of wave propagation after $7.2 \mathrm{~s}$ of dam break with wet bed and dry bed using the aforementioned two schemes are illustrated in Figures 9 and 10, respectively. It is worth mentioning that the wave propagation pattern obtained from Figures 7 and 9 is agree well with those stated by Turan and Wang, 2007.

\section{Dam break flow with $45^{\circ}$ bend channel test}

A reservoir with $2.44 \mathrm{~m} \times 2.39 \mathrm{~m}$ dimension and $0.495 \mathrm{~m}$ open gate connected to $45^{\circ}$ bend channel with a free outlet at the end, as shown in Figure 11, is considered to run the presented models. In this research, the horizontal domain is triangulated to 2199 cells and 1220 nodes, which are demonstrated in Figure 11, and the Manning coefficient is set at $0.0095 \mathrm{~m}^{1 / 3} \mathrm{~s}$. A $0.25 \mathrm{~m}$ and $0.01 \mathrm{~m}$ water depth is initiated in the reservoir and the channel, respectively. The computational results of both the Roe and HLLC Schemes

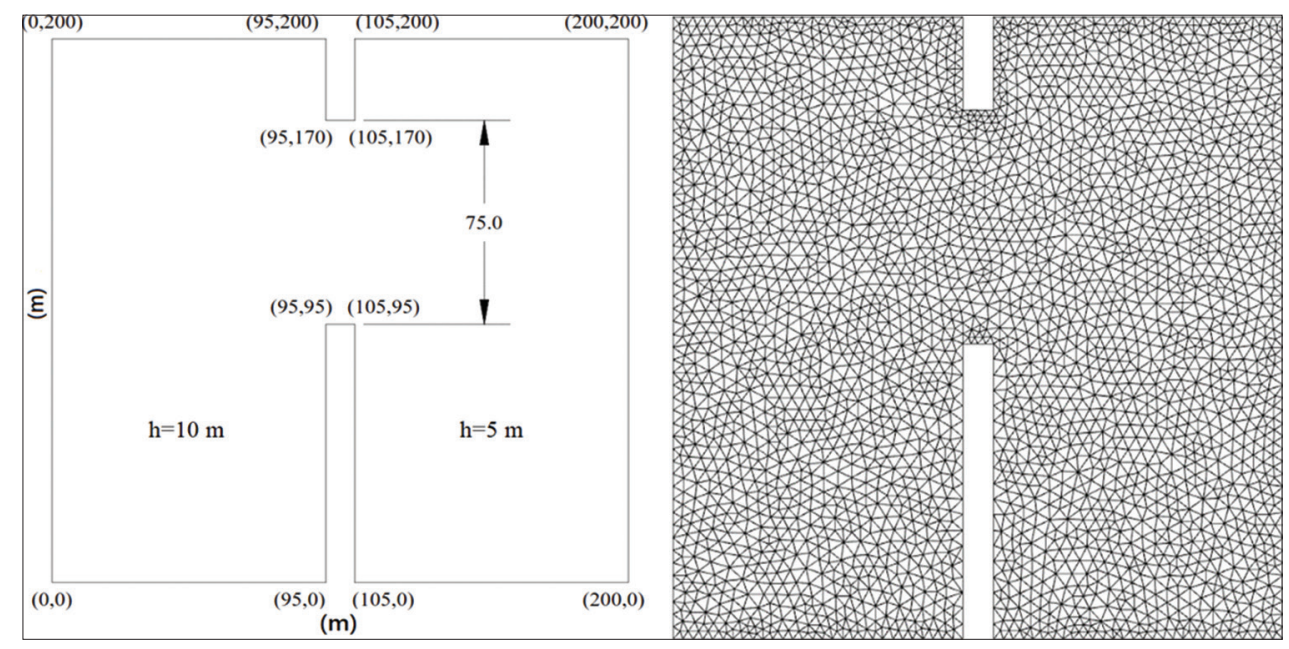

Figure 6: Left: Domain of partial dam break, Right: Mesh generation for partial dam break

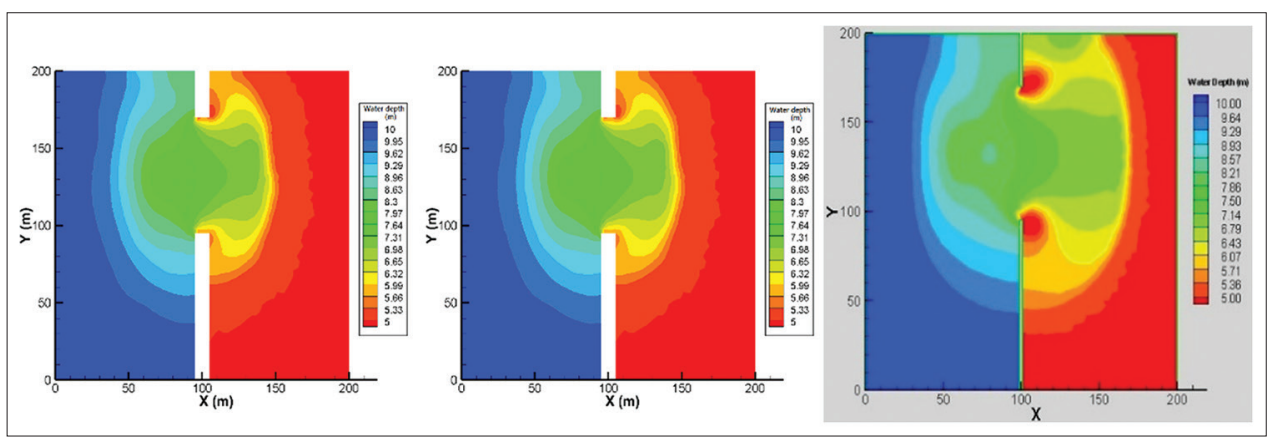

Figure 7: Water depth contour $7.2 \mathrm{~s}$ after dam break with wet bed (Left: Roe scheme) (Middle: HLLC scheme) (Right: Turan and Wang, 2007) 


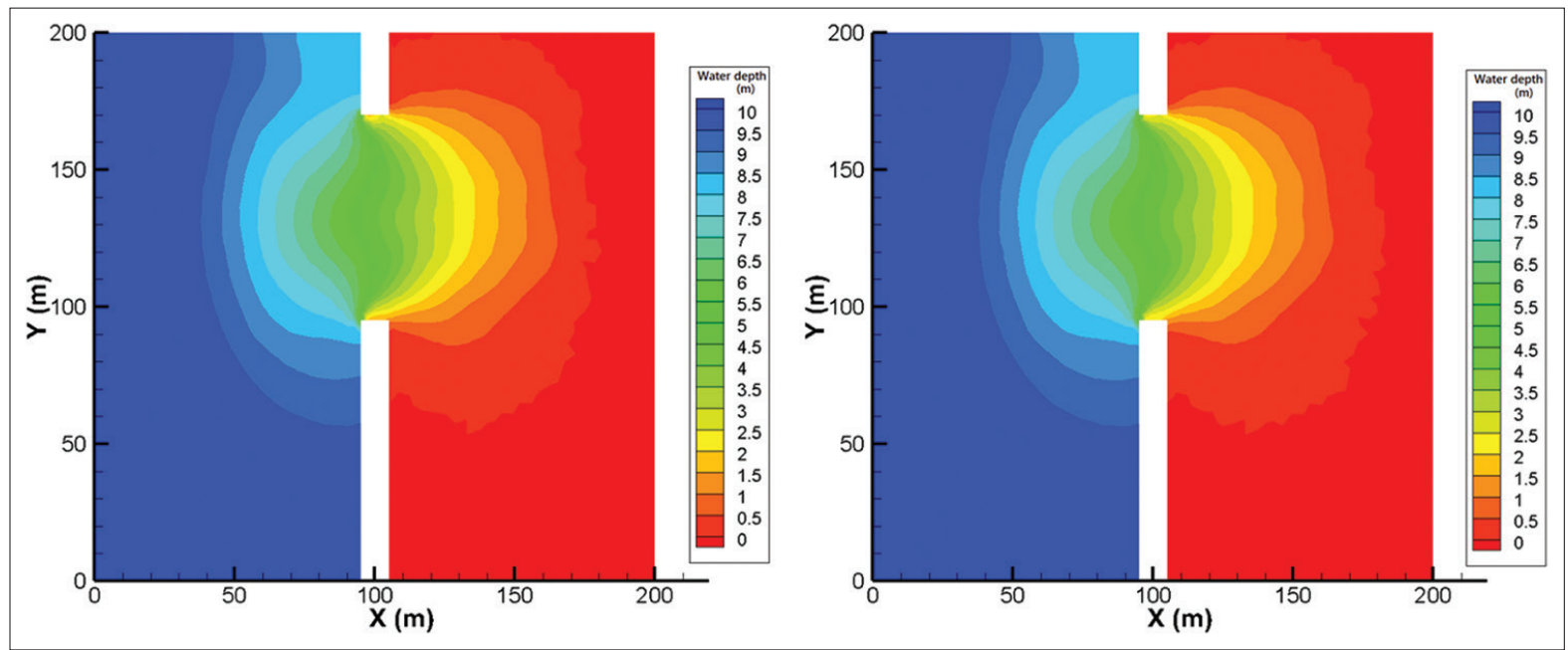

Figure 8: Water depth contour 7.2 s after dam break with dry bed (Left: Roe scheme) (Right: HLLC scheme)

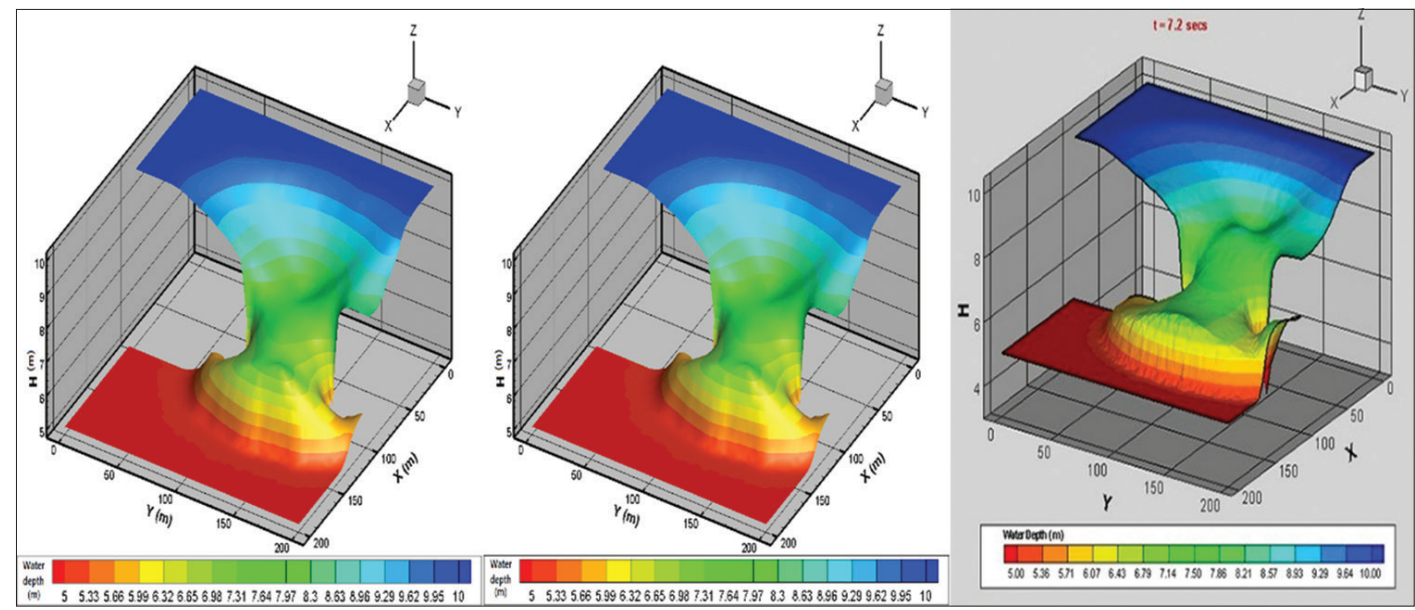

Figure 9: 3D view of wave propagation $7.2 \mathrm{~s}$ after dam break with wet bed (Left: Roe scheme) (Middle: HLLC scheme) (Right: Turan and Wang, 2007)

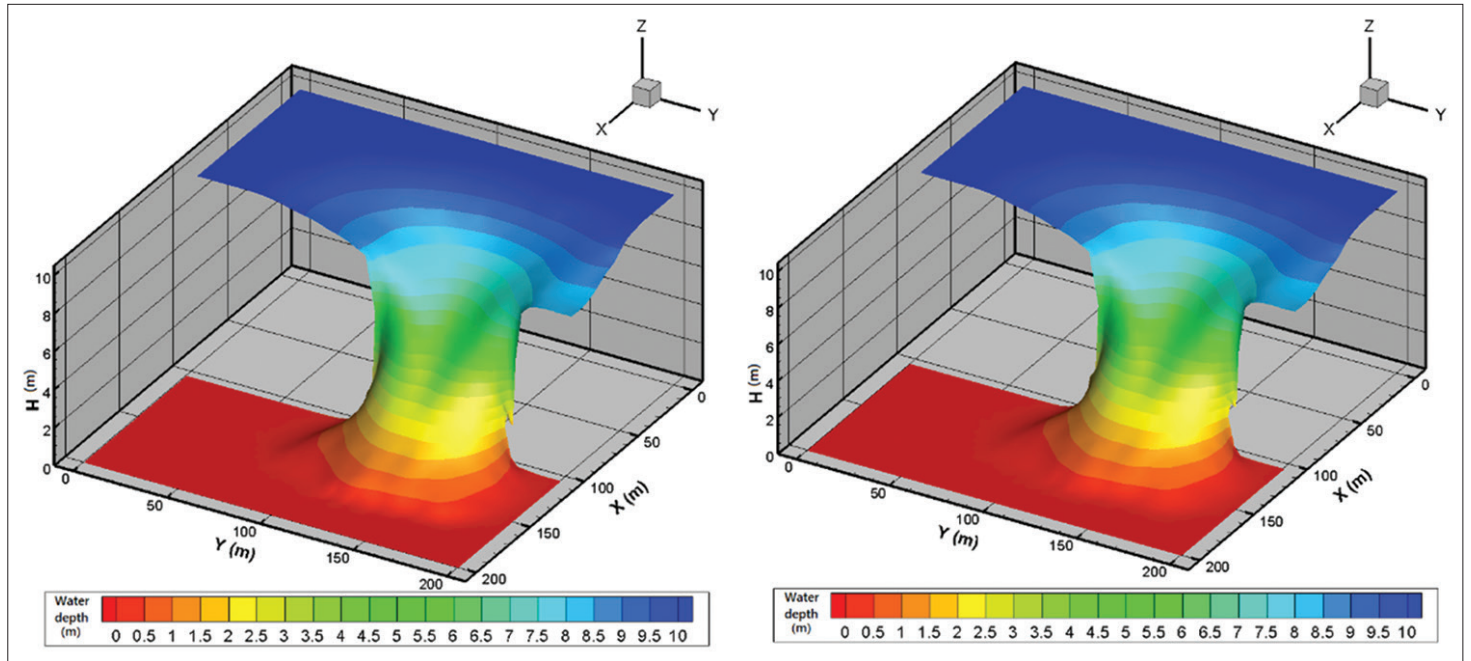

Figure 10: 3D view of wave propagation $7.2 \mathrm{~s}$ after dam break with dry bed (Left: Roe scheme) (Right: HLLC scheme)

after $3 \mathrm{~s}$ dam break with $0.01 \mathrm{~s}$ time step are plotted in Figure 12. As it can be seen, the results are approximately identical. Furthermore, the 3D view water depth of the dam break flow with $45^{\circ}$ bend channel using both 


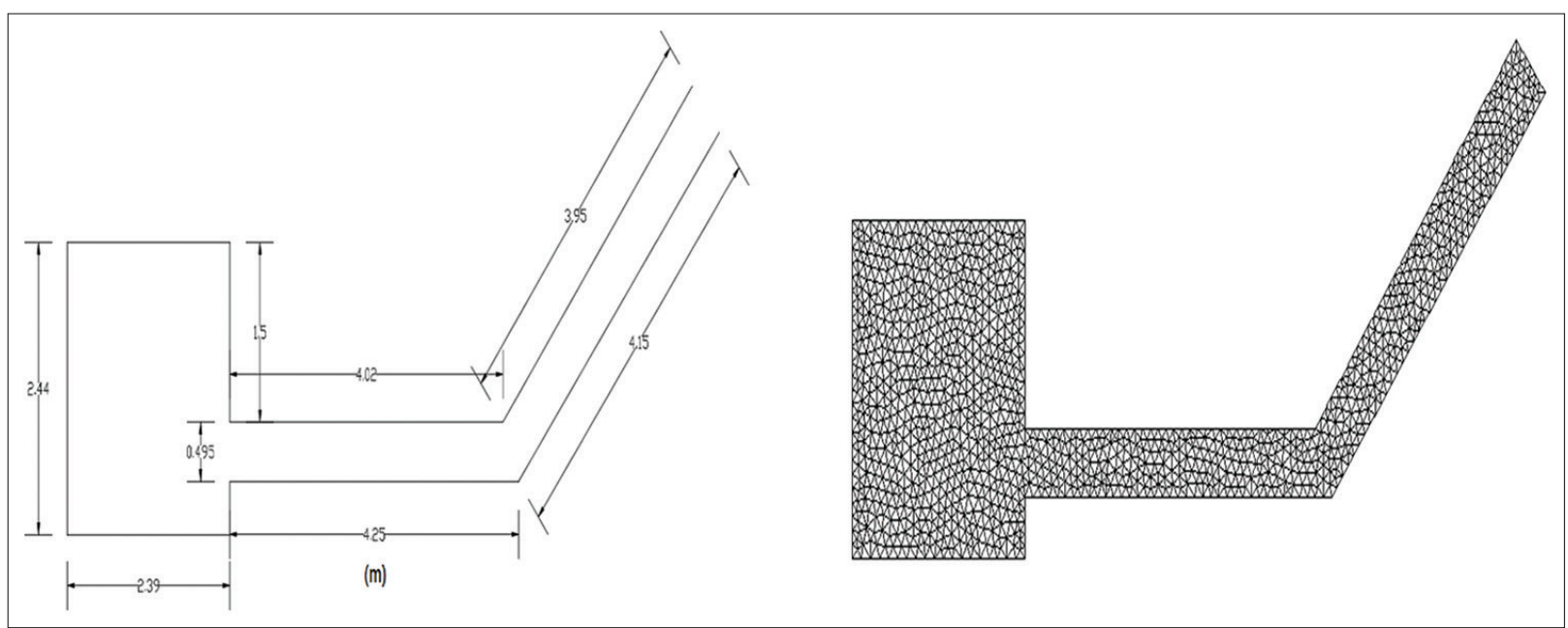

Figure 11: Left: Domain of $45^{\circ}$ bend channel, Right: Mesh generation

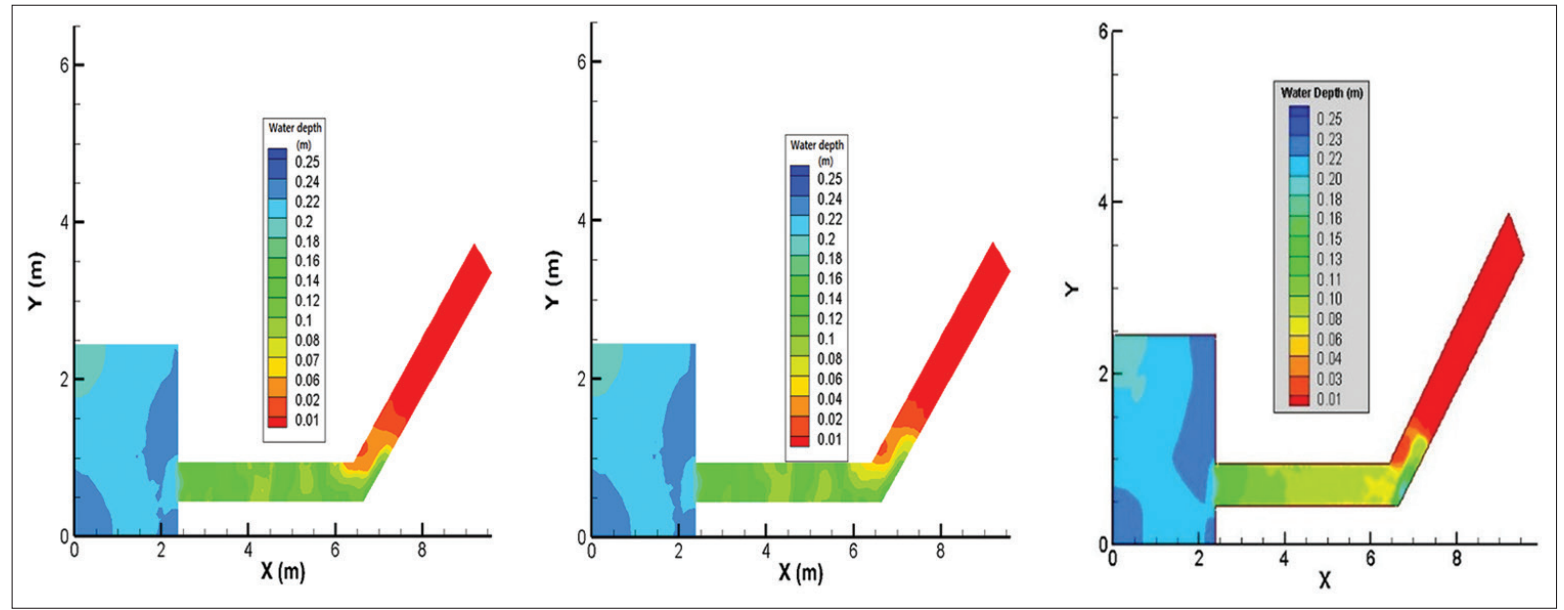

Figure 12: Water depth contour $3 \mathrm{~s}$ after dam break (Left: Roe scheme) (Middle: HLLC scheme) (Right: Turan and Wang, 2007)

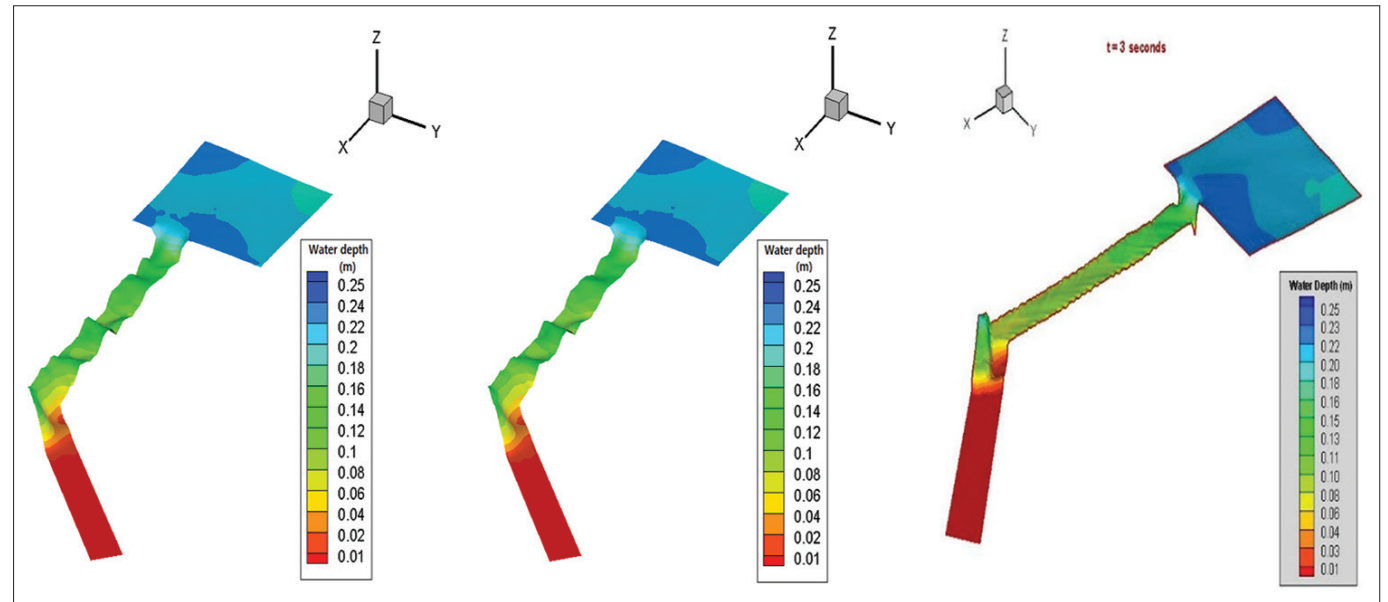

Figure 13: 3D view of wave propagation 3 s after dam break (Left: Roe scheme) (Middle: HLLC scheme) (Right: Turan and Wang, 2007)

schemes is presented in Figure 13. These figures clearly indicate that the numerical output from both schemes is the same. Moreover, these results are in agreement with those presented by Turan and Wang, 2007.

\section{EAP for Mosul Dam Break}

An EAP is an official Scheme to recognize possible danger circumstances in the area and specifies the process to be used to reduce the loss of life and property damage (Jerry 
and Olds, 2003). The EAP can be presented in different format types but it would be more efficient by providing a systematic plan. According to FEMA-64, 2013, the EAP generally includes six elements:

1. Notification flowcharts and contact information

2. Response process

3. Responsibilities

4. Preparedness activities

5. Inundation maps

6. Additional information in appendices.

In this research, the inundation maps of the Mosul dam break will be presented by implementing the numerical model. These maps can be used to predict the flooded area, time travel of the front wave, and maximum water depth at critical locations. The inundation maps are an important part of EAP and can be used by authorities of emergency management and dam operator to simplify the timely warning and evacuate the places that possibly influenced by the flood.

As a pre-processing step, an image of a bathymetric survey performed in 2011, as shown in Figure 14, is used to evaluate the Mosul dam bed topography. The ArcGIS 10.5 program from ESRI has been applied in digitization procedure and replacing the bottom elevation as STRM30 in the dam location, as shown in Figure 15. The computational domain triangulated by implementing the commercial software Surfacewater Modeling System 12.1 product by AQUAVEO ${ }^{\mathrm{TM}}$. The Manning's coefficient is set at $0.033 \mathrm{~m}^{-1 / 3} \mathrm{~s}$ and uniformly distributed for the overall of the computational area.

As explained earlier, the Mosul dam break may occur under the effect of seepage beneath the dam foundation. The seepage tends the foundation particles to move downstream because of the friction between the particles and water, this displacement creates voids in the foundation of the embankment and these voids are become pipeshaped space due to the increase of erosion rate. The pipe cavities gradually enlarged until produce a continuous space through the embankment base and it is sufficient to cause the zone above to collapse. In this study, the worst-case scenario is considered through a full break with $330 \mathrm{~m}$ maximum lake level and $254 \mathrm{~m}$ bed elevation, which is the level of the downstream river and the length of the dam body measured to be $2100 \mathrm{~m}$.

In this research, the simulation of the Mosul dam break considered for $7 \mathrm{~h}$. Because of the high CPU time consumption, the computational domain divided into two parts, the first part has taken until $8 \mathrm{~km}$ below the dam body and triangulated with a $90 \mathrm{~m}$ resolution and simulation was run by the presented model and took around 8 days of CPU time using a computer processor i7-8750 $\mathrm{H}$ with $32 \mathrm{~GB}$ installed RAM. The second part simulated

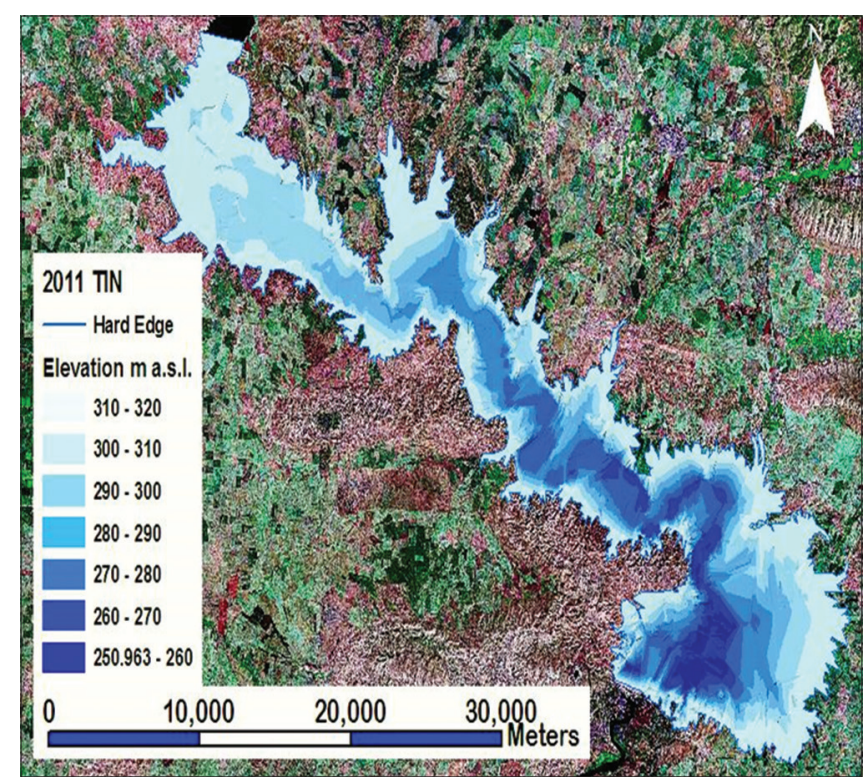

Figure 14: Bathymetric survey (Issa et al., 2013)

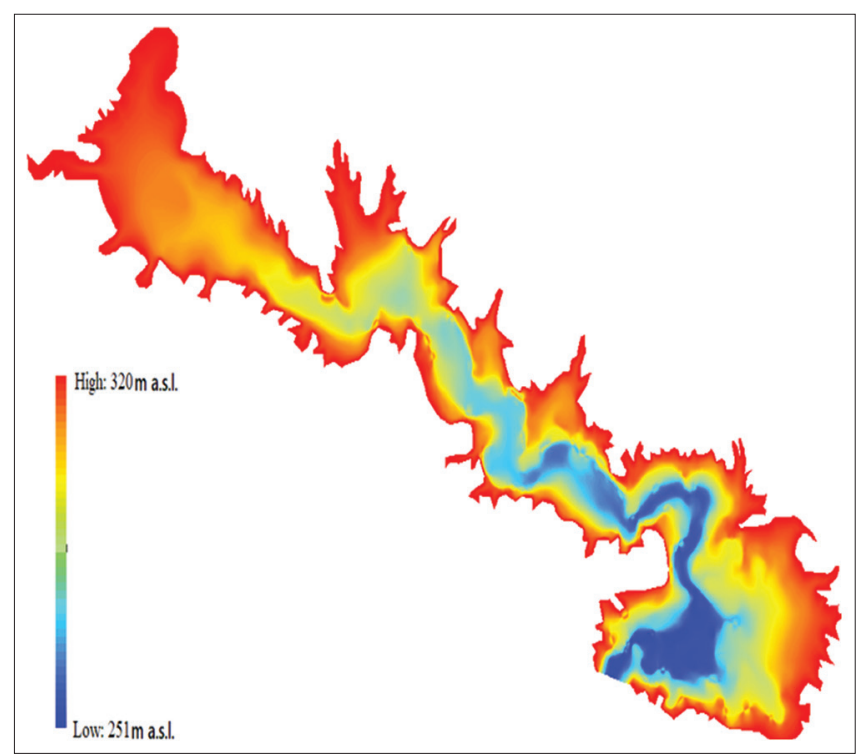

Figure 15: Mosul dam bed topography used in this study

using HEC-RAS 5.0.7 software with $90 \mathrm{~m} \mathrm{dx}$ and dy. The computational results obtained from the inundation maps due to the Mosul dam break reveal that flood wave may reach the center of Mosul city in $<6 \mathrm{~h}$ and simulation for $7 \mathrm{~h}$ time intervals is presented in Figure 16. These results demonstrate that:

- The inundated area with water depth larger than 0.3 $\mathrm{m}$ is nearly $535 \mathrm{~km}^{2}$.

- Considering the center of Mosul city, the affected population is about 415,000 persons and around $34 \mathrm{~m}$ maximum water depth.

- Critical infrastructure, parts of urban area, highway, Mosul international airport, and crop fields will be affected. 


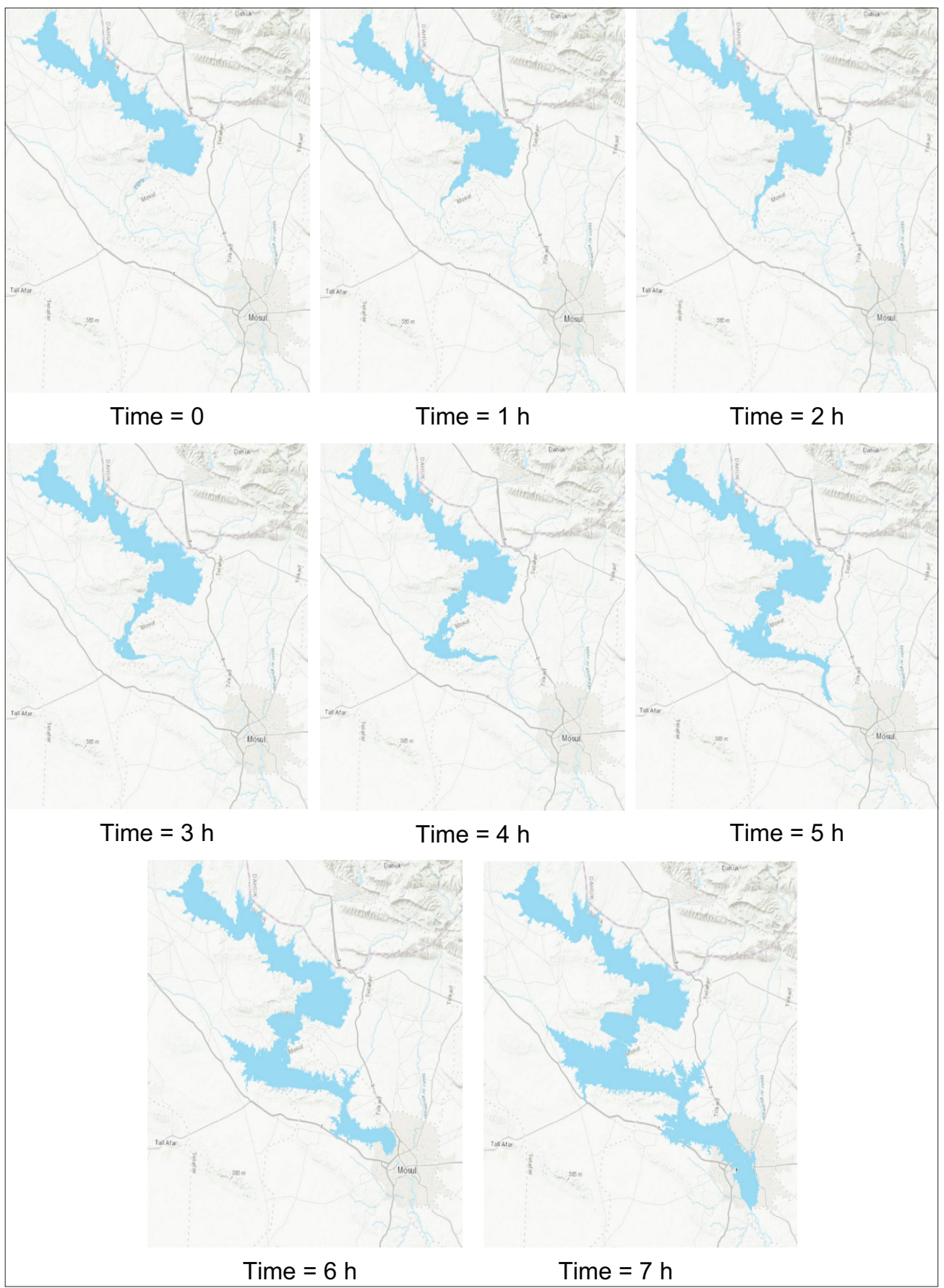

Figure 16: Mosul dam break inundation maps

\section{CONCLUSIONS}

The roe and HLLC model has been applied to two benchmark test cases with wet/dry front and Mosul dam break simulation. The FVM over unstructured triangular mesh for the spatial discretization with Roe and HLLC scheme is applied to calculate fluxes and Hancock's predictorcorrector for time computation provide good results in solving two-dimensional SWEs. The test case results reveal that there is no significant difference between roe and HLLC scheme and both models are able to capture shock waves and deal with complex topography, mixed flow regimes, and discontinuities. The Mosul dam break results show that the center of Mosul city will be exposed to flood waves in $<6 \mathrm{~h}$ and after $7 \mathrm{~h}$ the maximum water height about $34 \mathrm{~m}$. The inundation maps illustrated that after $7 \mathrm{~h}$ around $535 \mathrm{~km}^{2}$ will be flooded and considering Mosul city center about 415,000 individuals will be affected with critical project elements. 


\section{REFERENCES}

Adamo, N., N. Al-Ansari, V. Sissakian, S. Knutsson and J. Laue. 2017. Is Mosul Dam the most dangerous dam in the world? Review of previous work and possible solutions. Engineering. 9: 801-823.

Anastasiou, K. and C. Chan. 1997. Solution of the 2D shallow water equations using the finite volume method on unstructured triangular meshes. Int. J. Numer. Methods Fluids. 24; 12251245.

Annunziato, A., I. Andredakis and P. Probst. 2016. Impact of Flood by a Possible Failure of the Mosul Dam. JRC Technical Reports, EU Commission.

Bi, S., L. Song, J. Zhou, L. Xing, G. Huang, M. Huang and S. Kursan. 2015. Two-dimensional shallow water flow modeling based on an improved unstructured finite volume algorithm. Adv. Mech. Eng. 7: 1687814015598181.

FEMA-64. 2013. Federal Guidlines for Dam Safety: Emergency Action Planning for Dams, FEMA.

Guzina, B., M. Saric and N. Petrovic. 1991. Seepage and Dissolution at Foundations of a Dam during the First Impounding of the Reservoir. Congres des Grandes Barages, Vienne, Austria.

Hirsch, C. 2007. Numerical Computation of Internal and External Flows: The Fundamentals of Computational Fluid Dynamics. Elsevier, Amsterdam, Netherlands.

Hou, J., F. Simons, M. Mahgoub and R. Hinkelmann. 2013. A robust well-balanced model on unstructured grids for shallow water flows with wetting and drying over complex topography. Comput. Methods Appl. Mech. Eng. 257: 126-149.

Issa, I. E., N. Al-Ansari and S. Knutsson. 2013. Changes in bed morphology of Mosul dam reservoir. J. Adv. Sci. Eng. Res. 3: 86-95.
Jerry, O. 2003. Emergency Action Plan: Development and Implementation. Dam Safety Guide, State Engineer, Utah.

Liang, Q. and A. G. Borthwick. 2009. Adaptive quadtree simulation of shallow flows with wet-dry fronts over complex topography. Comput. Fluids. 38: 221-234.

Mohammad, J. R. 2007. Simulation of Hypothetical Duhok Dam Break. PhD Thesis, Mosul University.

Song, L., J. Zhou, J. Guo, Q. Zou and Y. Liu. 2011. A robust wellbalanced finite volume model for shallow water flows with wetting and drying over irregular terrain. Adv. Water Resour. 34: 915-932.

Song, L., J. Zhou, Q. Li, X. Yang and Y. Zhang. 2010. An unstructured finite volume model for dam-break floods with wet/dry fronts over complex topography. Int. J. Numer. Methods Fluids. 67: 960-980.

Swiss-Consultants. 1984. Flood Wave Studies, Mosul Flood Wave, Confindential Report for the Ministry of Irigation, State Organization of Dams, the Model and Model Calibration.

Toro, E. F. 2001. Shock-capturing Methods for Free-surface Shallow Flows. John Wiley, New York.

Turan, B. and K. H. Wang. 2007. Flood and Shock Waves Simulation by Using Finite Volume Technique on Unstructured Meshes. World Environmental and Water Resources Congress 2007: Restoring Our Natural Habitat. p1-10.

Valiani, A., V. Caleffi and A. Zanni. 2002. Case study: Malpasset dambreak simulation using a two-dimensional finite volume method. J. Hydraul. Eng. 128: 460-472.

Wakeley, L. D., J. R. Kelley, C. A. Talbot, M. L. Pearson and S. W. Broadfoot. 2007. Geologic Conceptual Model of Mosul Dam. Engineer Research and Development Center Vicksburg ms Geotechnical and Structures Lab, Vicksburg, Mississippi. 